\title{
Effect of $\gamma$-ethyl- $\gamma$-phenyl-butyrolactone (EFBL), anticonvulsant and hypnotic drug, on mouse brain catecholamine levels
}

\author{
LOURDES A. VEGA RASGADO ${ }^{1 *}$ \\ IVÁN VILLANUEVA ${ }^{2}$ \\ FERNANDO VEGA DÍAZ ${ }^{1}$ \\ ${ }^{1}$ Laboratorio de Neuroquímica \\ Departamento de Bioquímica \\ Escuela Nacional de Ciencias Biológica \\ Instituto Politécnico Nacional \\ Carpio y Plan de Ayala S/N \\ Colonia Casco de Santo Tomás \\ C.P. 11340, México, D.F., México \\ ${ }^{2}$ Departamento de Fisiología \\ Escuela Nacional de Ciencias \\ Biológicas, Instituto Politécnico \\ Nacional, Carpio y Plan de Ayala S/N \\ Colonia Casco de Santo Tomás \\ C.P. 11340, México, D.F., México
}

Accepted December 16, 2016

Published online February 7, 2017

\begin{abstract}
$\gamma$-Ethyl- $\gamma$-phenyl-butyrolactone (EFBL) is a structural combination of the anticonvulsant $\gamma$-hydroxy- $\gamma$-ethyl- $\gamma$-phenylbutyramide (HEPB) and the hypnotic $\gamma$-butyrolactone (GBL), which inherits both properties. To clarify its mechanism of action, the effects of EFBL, GBL and HEPB on dopamine (DA) and noradrenaline (NA) brain levels were investigated. Influences of chlorpromazine, phenelzine and aminooxyacetic acid were also studied. EFBL increased DA in a dose-dependent manner, remaining enhanced by $80 \%$ over a period of $24 \mathrm{~h}$ and augmented NA by $54 \%$ one hour after treatment. HEPB increased DA and NA approximately 2-fold after the first hour. GBL raised DA and NA after three and $24 \mathrm{~h}$, resp. EFBL reversed chlorpromazine effects but potentiated those of phenelzine on DA. Amino-oxyacetic modified neither DA nor NA brain levels, not even in the presence of EFBL. The anticonvulsant and hypnotic properties of EFBL are attributed to its effect on presynaptic dopaminergic receptors and its lasting effect on ethyl and phenyl radicals that hinder its degradation. The results support the role of DA and NA in regulating seizure activity in the brain and indicate that EFBL offers a potential treatment for refractory epilepsy without complementary drugs and Parkinson's disease, without the drawbacks of oral therapies.
\end{abstract}

Keywords: $\gamma$-ethyl- $\gamma$-phenyl-butyrolactone (EFBL), anticonvulsant, hypnotic, mouse brain, catecholamine

It is known that $\gamma$-butyrolactone (GBL) has depressant effects on the central nervous system (CNS), causing sleepiness and anesthesia (1), whereas ethyl-phenyl-pyrrolidinone (EPP), the cyclic form of $\gamma$-aminobutyric acid (GABA), is an anticonvulsant whose structure is known as $\gamma$-hydroxy- $\gamma$-ethyl- $\gamma$-phenylbutyramide (HEPB). As a result of the structural combination of HEPB and GBL, $\gamma$-ethyl- $\gamma$-phenyl-butyrolactone (EFBL) was synthesized (2), showing both anticonvulsant $(2,3)$ and hypnotic (4) properties. Because of the abovementioned pharmacological properties, the mechanism of action of EFBL was investigated.

\footnotetext{
*Correspondence; e-mail addresses: lourdes_vega_rasgado@hotmail.com
} 
It is fundamental to understand the role of GABA, a major inhibitory neurotransmitter in the CNS of mammals, in neuronal excitability, to fully comprehend its mechanism of action and rational design of anticonvulsant agents (5). Since an association between the activity of the GABA-synthesizing enzyme $L$-glutamate decarboxylase (DAG) and seizure generation was established, increasing the brain GABA levels has become a common strategy utilized in the rational design of anticonvulsants. One approach to accomplishing this goal has been the inhibition of the GABA-degrading enzyme GABA-transaminase (T-GABA). T-GABA inhibitors, such as hydroxylamine and amino-oxyacetic acid (AAOA), have been shown to protect against seizures induced by different chemoconvulsants (6). In any case, most anticonvulsants used in epilepsy treatment are related to GABA-ergic transmission. Therefore, we aimed to clarify the mechanism of action of EFBL and its relationship with GABA metabolism. Neither GABA levels nor DAG or T-GABA activity were modified by EFBL, suggesting that this drug acts by interacting with other neurotransmitters (3). This may be related to the fact that HEPB, one of EFBL parent drugs, does not influence the GABA-ergic system (3).

There is considerable evidence supporting the participation of the GABA-ergic system in convulsions, but no simple relationship between brain GABA levels and seizures has been established yet. Some examples include reports of seizures that occur during pharmacological conditions that do not interfere with the GABAA receptor function and, in some cases, they appear to enhance it (7). Epileptiform discharges were observed during the application of $\mathrm{Mg}^{2+}$-free medium, even with the preservation of inhibitory post-synaptic potential caused by GABAA receptor stimulation (8). In addition, it has been determined that selective stimulation of GABAA receptors in the hippocampus causes an increase in extracellular $\mathrm{K}^{+}$, which induces convulsions, even when ionotropic glutamatergic transmission is blocked $(9,10)$. This means that postsynaptic activation of GABAA receptors can also cause membrane depolarization of both interneurons and principal cells in immature cells (11) and some adult long-axoned neurons (12) or interneurons. These depolarizing postsynaptic currents may be strong enough to result in excitation, which could lead to seizures.

Thus, the anticonvulsant effect of EFBL that seems to spare GABA metabolism suggests that some other factors besides GABA-ergic activity are affected by this drug, which reduces seizures.

Interestingly, studies have also indicated a role for dopamine (DA) $(13,14)$ and noradrenaline (NA) (15) in regulating seizure activity in the brain. Moreover, the depressive effect of GBL, a precursor drug of EFBL, is attributed to the selective increase in DA concentration that it causes in mouse, rat and rabbit brains (1).

Considering the potential use of EFBL as an antiepileptic drug, and the possibility that EFBL could act through increasing DA brain levels as does GBL, representing a possible treatment for Parkinson's disease, this work aims to examine the effect of EFBL and its parent drugs GBL and HEPB on DA and NA levels in the mouse brain.

Development of new antiepileptic drugs (AEDS) is always important, since some cases are refractory to the treatments with traditional AEDS, either administrated alone or in combination. On the other hand, a new non-oral treatment of Parkinson's disease, such as EFBL, may be highly important, since in the course of the disease oral medication loses effectiveness due to several reasons like dysphagia or impaired absorption from the gastro-intestinal tract and delayed emptying of the stomach. In those situations, a non-oral therapy should be considered. 


\section{EXPERIMENTAL}

\section{Animals}

Experiments were conducted in accordance with the Helsinki Guide for the Care and Use of Laboratory Animals, as adopted and promulgated by EU Directive 2010/63/EU for animal experiments, and approved by the Institutional Ethics Committee of the National School of Biological Sciences, Colonia Casco de Santo Tomás, México.

Male CD1 albino mice with a mean body mass of $25 \mathrm{~g}$ (aged 5-6 weeks) were used for the experiments. Animals were maintained on a 12/12 h light/dark cycle and fed a stock laboratory diet $(\%, \mathrm{~m} / \mathrm{m}$ : 49.8 carbohydrates, 23.5 proteins, 3.7 fats, minerals, vitamins, and amino acids) ad libitum. Animals had free access to drinking water.

Each experimental group comprised five animals, which received EFBL, GBL or HEPB at different doses and times of treatment (1-24 h). Chlorpromazine (CPZ), phenelzine (PHEN) or amino-oxyacetic acid (AAOA) were administered to groups of five animals each, either alone or followed by EFBL. Control groups comprised five animals and each received peanut oil or saline solution, depending on the experiment.

All drugs were administered by intraperitoneal (i.p.) injection.

\section{Reagents}

EFBL was synthesized by Vega-Díaz and Vega-Rasgado (2) and identified by infrared and nuclear magnetic resonance (NMR) spectroscopy. The drug was dissolved in peanut oil.

HEPB was laboratory obtained and its structure and purity were corroborated by infrared and NMR analysis. It was dissolved in a saline. GBL was purchased from SigmaAldrich (USA) and dissolved in peanut oil. CPZ, PHEN and AAOA were purchased from Sigma-Aldrich and dissolved in a saline solution before administration.

Standard analytical grade laboratory reagents were obtained from Merck (Germany) or Sigma-Aldrich.

\section{Effects of different doses of EFBL, HEPB and GBL on DA and NA brain levels}

Different doses of EFBL (400, 600 and $\left.800 \mathrm{mg} \mathrm{kg}^{-1} \mathrm{bm}\right)$, HEPB (90, 135 and $180 \mathrm{mg} \mathrm{kg}^{-1}$ $\mathrm{bm})$ or GBL (180, 270 and $360 \mathrm{mg} \mathrm{kg}^{-1} \mathrm{bm}$ ) were administered to different groups of animals. The doses correspond to 2.1, 3.15 and $4.2 \mathrm{mmol} \mathrm{kg}^{-1} \mathrm{bm}$, resp. for each of the drugs. One hour after administration, animals were sacrificed, the brains were quickly removed and processed for DA and NA determination, as described below.

Corresponding control groups received peanut oil when EFBL and GBL were used and saline solution when GBL was used.

\section{Temporal profile of brain DA and NA levels after HEPB, GBL and EFBL administration}

Groups of animals receiving a single dose of 800, 180 and $360 \mathrm{mg} \mathrm{kg}^{-1} \mathrm{bm}$ of EFBL, HEPB or GBL, resp., corresponding to $4.2 \mathrm{mmol} \mathrm{kg}^{-1} \mathrm{bm}$ in each case, were sacrificed 1, 2, 
4, 6, 12, and 24 hours after administration, at which point DA and NA brain levels were determined. Corresponding control groups received peanut oil when EFBL and GBL were used and saline solution when GBL was used.

\section{Influence of different drugs on the effects of EFBL on DA and NA brain levels}

CPZ (20 mg kg-1 bm), PHEN (50 $\mathrm{mg} \mathrm{kg}^{-1} \mathrm{bm}$ ) or AAOA ( $\left.35 \mathrm{mg} \mathrm{kg}^{-1} \mathrm{bm}\right)$ were administered either alone or followed by administration of EFBL $\left(800 \mathrm{mg} \mathrm{kg}^{-1} \mathrm{bm}\right.$, corresponding to $4.2 \mathrm{mmol} \mathrm{kg}^{-1} \mathrm{bm}$ ) one hour later. After 1 hour, animals were sacrificed and DA and NA brain levels were quantified. The effects of individual drugs (CPZ, PHEN or AAOA) or EFBL or their combination (CPZ-EFBL, PHEN-EFBL and AAOA-EFBL) were compared with the control group, which received peanut oil.

\section{Determination of DA and NA concentrations in the brain}

Tissue processing. - After treatment, animals were sacrificed by decapitation and whole brains were removed. Tissues were homogenized in perchloric acid (PCA, $0.4 \mathrm{~mol} \mathrm{~L}^{-1}$ ) with the aid of a tissue homogenizer (Glas-Col, USA).

Catecholamine extraction. - Brain homogenates were centrifuged (4,000 rpm, $10 \mathrm{~min})$ and DA and NA were extracted from the supernatants by adsorption onto acid alumina using ESA EXTRACT-CLEAN columns (Grace Davidson Discovery Sciences, USA) as described previously (16).

Catecholamine detection. - Eluates from the catecholamine extraction were analyzed by high performance liquid chromatography (HPLC) coupled with electrochemical detection (ESA Coulochem II multielectrode detector, Chelmsford MA, USA) using a reverse phase C18 column (Grace Davidson Discovery Sciences, USA) and a mobile phase consisting of phosphate buffer $0.02 \mathrm{~mol} \mathrm{~L}^{-1}$ at $\mathrm{pH}=4, \mathrm{Na}_{2}$ EDTA $0.01 \mathrm{~mol} \mathrm{~L}^{-1}$, sodium octyl sulfate $1.3 \mathrm{mmol} \mathrm{L}^{-1}$, sodium dodecyl sulfate $0.1 \mathrm{mmol} \mathrm{L}^{-1}$ and methanol $10 \%$, at a flow rate of $0.5 \mathrm{~mL} \mathrm{~min}^{-1}(16)$. The results are expressed as catecholamine $\mu \mathrm{g} \mathrm{g}^{-1}$ of wet tissue.

\section{Statistical analysis}

All results are expressed as the mean \pm standard error of the mean (SEM) of at least five determinations $(n \geq 5)$. DA and NA levels were compared between groups using the one-way analysis of variance (ANOVA), followed by Tukey's multiple comparisons test. Graph Pad Prism version 5.0 software (GraphPad Software, Inc., La Jolla, CA, USA) was used, and $p<0.05$ was considered statistically significant.

\section{RESULTS AND DISCUSSION}

Although this study focused on the properties of EFBL, the analysis of its effects on catecholamine brain levels included a comparison with its parent drugs, HEPB and GBL, administered under the same conditions. Equimolar doses of all drugs were used because ethyl and phenyl radicals considerably increase the molecular mass of EFBL and administration of similar masses of the drugs would have resulted in different molar concentrations. 
a)

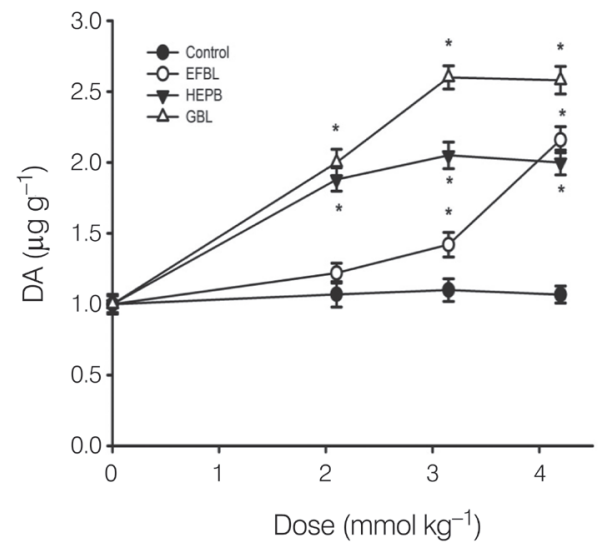

b)

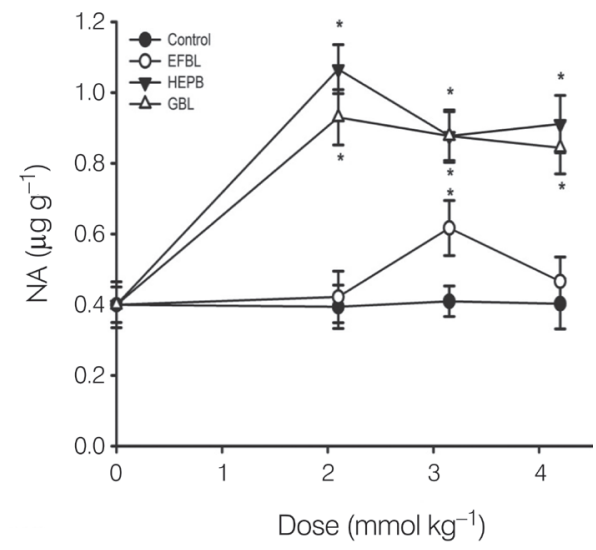

Fig. 1. Effect of different doses of $\gamma$-ethyl- $\gamma$-phenyl-butyrolactone (EFBL), $\gamma$-hydroxy- $\gamma$-ethyl- $\gamma$ phenylbutyramide (HEPB) and $\gamma$-butyrolactone (GBL) on the brain levels of: a) dopamine (DA) and b) noradrenaline (NA). Groups of five mice received different doses of EFBL $(400,600$ and $800 \mathrm{mg}$ $\mathrm{kg}^{-1}$ ), HEPB (90, 135 and $180 \mathrm{mg} \mathrm{kg}^{-1}$ ) or GBL (180, 270 and $\left.360 \mathrm{mg} \mathrm{kg}^{-1}\right)$, equivalent to 2.1, 3.15 and 4.2 mmol kg ${ }^{-1}$ of each (mean \pm SEM, $n \geq 5$ ). Statistically significant difference $v$ s. control: ${ }^{*} p<0.05$.

Tested doses of EFBL were selected because of their anticonvulsant $\left(350 \mathrm{mg} \mathrm{kg}^{-1}\right.$, equivalent to $2.1 \mathrm{mmol} \mathrm{kg}^{-1}$ ) and hypnotic $\left(700 \mathrm{mg} \mathrm{kg}^{-1}\right.$, corresponding to $4.2 \mathrm{mmol} \mathrm{kg}{ }^{-1}$ ) properties, as previously shown $(2,4)$.

Effects of EFBL, GBL and HEPB were compared with those of other drugs with wellknown effects on catecholamine brain levels. The drugs used for this purpose were the DA receptor antagonist chlorpromazine and the classic monoamine oxidase (MAO) inhibitor phenelzine. Because of the possible stimulation of GABAA receptors as a result of the influence of these psychoactive drugs $(17,18)$, AAOA was also investigated.

EFBL displays hypnotic properties that are stronger than those of GBL. A dose of 2.8 $\mathrm{mmol} \mathrm{kg}{ }^{-1}$ of EFBL is required to suppress the righting reflex in mice for 3 hours, whereas $4.42 \mathrm{mmol} \mathrm{kg}^{-1}$ of GBL is needed for a hypnotic effect lasting 1.5 hours (4). The hypnotic effect of GBL has been attributed to an increase in brain DA levels (19). Thus, a higher DA brain level would be expected after EFBL administration. The results presented in Fig. 1a show that HEPB and GBL increased significantly the DA levels from the lowest dose assayed $\left(2.1 \mathrm{mmol} \mathrm{kg}^{-1}\right)$, reaching their maximum effect at 2.1 and $3.15 \mathrm{mmol} \mathrm{kg}{ }^{-1}$, resp. The DA increase caused by HEPB and GBL was approximately twice that of the control levels. EFBL increased DA brain levels in a dose-dependent manner, causing a modest increase at $3.15 \mathrm{mmol} \mathrm{kg}^{-1}$ but reaching a high value, similar to the maximum of the other two drugs, at $4.2 \mathrm{mmol} \mathrm{kg}^{-1}$. In contrast, HEPB and GBL caused a significant increase in the brain concentration of NA (Fig. 1b), reaching a maximum increase of approximately $150 \%$ from the lowest dose assayed $\left(2.1 \mathrm{mmol} \mathrm{kg}^{-1}\right)$. Compared to these drugs, EFBL had a modest effect on the brain concentration of NA, increasing it by only $54 \%$ at a dose of $3.15 \mathrm{mmol} \mathrm{kg}^{-1}$.

The observation that brain DA levels were the highest after acute administration of GBL is consistent with previous reports $(1,19)$ and suggests that high levels of DA are re- 
a)

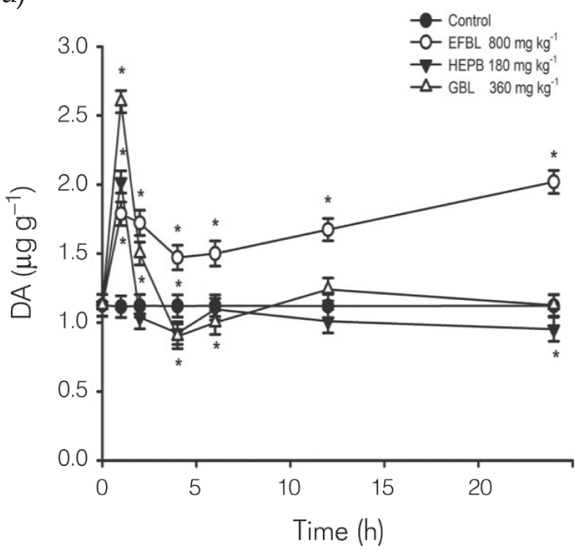

b)

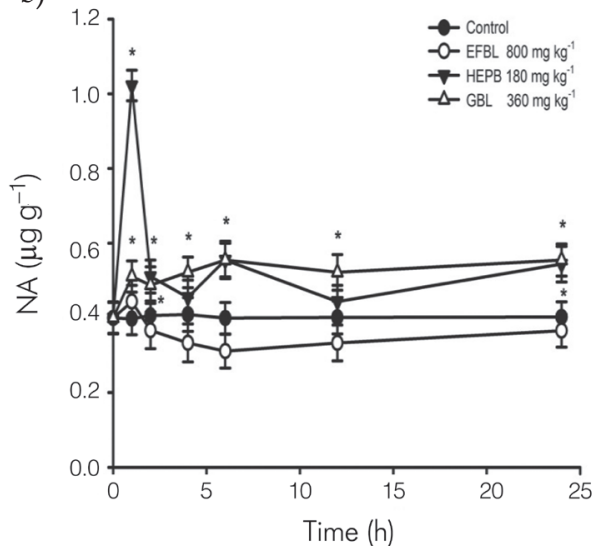

Fig. 2. Brain levels of: a) dopamine (DA) and b) noradrenaline (NA) over a 24-h period after the administration of $\gamma$-ethyl- $\gamma$-phenyl-butyrolactone (EFBL), $\gamma$-hydroxy- $\gamma$-ethyl- $\gamma$-phenylbutyramide (HEPB) or $\gamma$-butyrolactone (GBL). Groups of five animals received a single administration of EFBL $\left(800 \mathrm{mg} \mathrm{kg}^{-1}\right)$, HEPB $\left(180 \mathrm{mg} \mathrm{kg}^{-1}\right)$ or GBL $\left(360 \mathrm{mg} \mathrm{kg}^{-1}\right)$, equivalent to $4.2 \mathrm{mmol} \mathrm{kg}$. Brains were removed 1, 2, 4, 6, 12 and 24 hours after treatment (mean \pm SEM, $n \geq 5$ ). Statistically significant difference vs. control: ${ }^{*} p<0.05$.

quired for the hypnotic effect. Thus, if there is a direct relation between DA levels and the magnitude of the hypnotic effect, the fact that EFBL increased DA brain concentrations to a lesser extent than GBL, though EFBL has been reported as a better hypnotic than GBL (4), would be controversial. This paradox can be solved by the results shown in Fig. 2, where the temporal profile of brain catecholamines after a single administration of the highest dose of HEPB, GBL or EFBL can be appreciated. All three drugs increased significantly the brain DA levels shortly after administration, but after $2-4$ hours, the DA values had returned to the control values in the HEPB- and the GBL-treated groups. In both cases, there was a slight reduction below the control levels. The administration of EFBL, however, caused a 1.8-fold increase in brain DA levels shortly after administration, and these values (> $50 \%$ higher than the control values) were maintained even 24 hours later (Fig. 2a). Brain NA (Fig. 2b) was affected in a different way by the three drugs. HEPB caused a $155 \%$ increase that returned to control levels 4 hours after administration, GBL caused a mild increase (no more than $39 \%$ ) that lasted for the entire 24-h period but EFBL did not modify brain NA levels at any of the times examined.

Previous results suggest that, instead of producing the highest acute increase in brain DA levels, EFBL causes a sustained increase that lasts up to 24 hours after administration, whereas the effects of GBL and HEPB cease within two hours. The long-lasting effect of EFBL, compared to GBL, can be explained by its structure and by considering the GBL metabolism. Previous observations indicate that GBL must be converted to $\gamma$-hydroxybutyrate by a blood lactonase before it is able to exert an effect on brain DA metabolism and the behavior of the animal (1). Based on the same rationale, the presence of ethyl and phenyl radicals would cause EFBL to be metabolized even more slowly by lactonase, which would extend its effects. 
a)

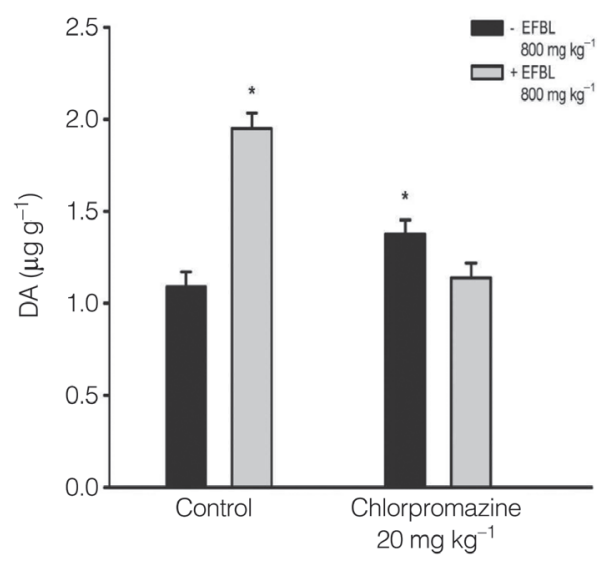

b)

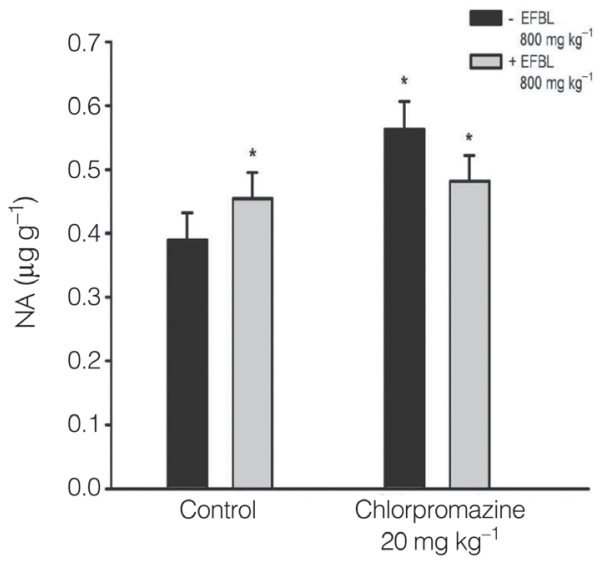

Fig. 3. Influence of chlorpromazine (CPZ) on the effect of $\gamma$-ethyl- $\gamma$-phenyl-butyrolactone (EFBL) on the brain levels of: a) dopamine (DA) and b) noradrenaline (NA). CPZ $\left(20 \mathrm{mg} \mathrm{kg}^{-1}\right)$ was administered to groups of five mice. One hour later, animals received a single administration of $800 \mathrm{mg} \mathrm{kg}^{-1}(4.2$ mmol kg-1) of EFBL and were sacrificed 1 hour later (mean \pm SEM, $n \geq 5$ ). Statistically significant difference vs. control: ${ }^{*} p<0.05$.

a)

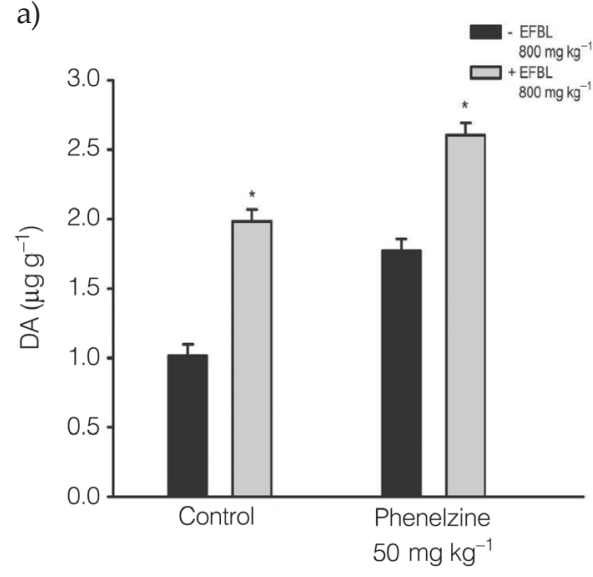

b)

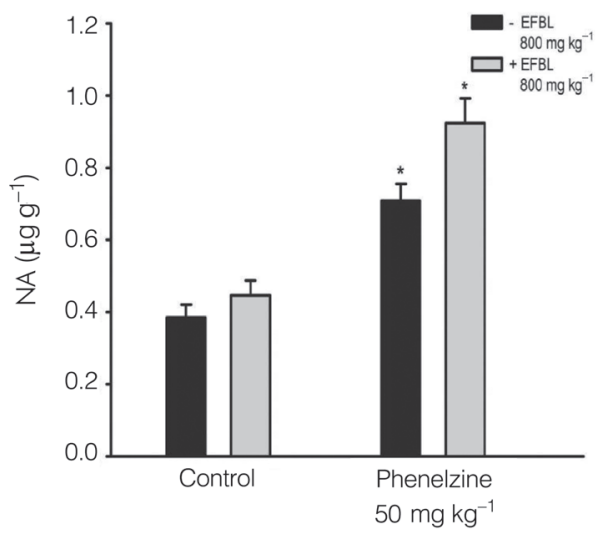

Fig. 4. Influence of phenelzine (PHEN) on the effect of $\gamma$-ethyl- $\gamma$-phenyl-butyrolactone (EFBL) on the brain levels of: a) dopamine (DA) and b) noradrenaline (NA). PHEN (50 $\mathrm{mg} \mathrm{kg}^{-1}$ ) was administered to groups of five mice. One hour later, animals received a single administration of $800 \mathrm{mg} \mathrm{kg}^{-1}(4.2 \mathrm{mmol}$ $\mathrm{kg}^{-1}$ ) of EFBL and were sacrificed 1 hour later (mean $\pm \mathrm{SEM}, n \geq 5$ ). Statistically significant difference vs. control: ${ }^{*} p<0.05$.

Some experimental models based on the administration of reserpine, benazine and alpha-methyl- $p$-tyrosine have demonstrated that a deficit in catecholaminergic neurotransmission increases the susceptibility to the generation of epileptic seizures $(20,21)$. 
Other reports have shown a reduction in catecholamine levels in the striatum during the latency period of the seizures induced by monosodium glutamate (22) The uptake and release of NA and DA during seizures have been shown to be modified in this model (23). In this work, in addition to the hypnotic properties of EFBL, we tested whether its actions on catecholaminergic neurotransmission were related to its anticonvulsant properties (4). Effects of CPZ, PHEN and AAOA on the changes in brain catecholamine levels induced by administration of $800 \mathrm{mg} \mathrm{kg}^{-1}\left(4.2 \mathrm{mmol} \mathrm{kg}^{-1}\right)$ of EFBL are given in Figs. 3, 4 and 5, resp. CPZ slightly enhanced brain DA levels, and its previous administration reversed the increase in DA brain levels caused by EFBL (Fig. 3a). PHEN caused brain DA levels to increase by approximately $59 \%$ and had a synergic effect on EFBL administration, causing a final increase of $156 \%$ (Fig. 4a). AOAA did not modify brain DA levels nor did it affect the increase caused by EFBL (Fig. 5a). The effects of these drugs on brain concentrations of NA were similar to those of DA. CPZ elevated NA levels and this effect was reversed by the administration of EFBL (Fig. 3b). The PHEN-induced rise in brain NA levels was potentiated by EFBL to a final concentration of 2 -fold that of the controls (Fig. 4b). AOAA did not modify NA levels nor did it influence the increasing effect of EFBL on this catecholamine (Fig. 5b).

EFBL and its parent anticonvulsant drug HEBP caused an acute increase in brain DA levels, which may be related to the anticonvulsant effects of both drugs. However, compared to EFBL, HEPB caused a much higher increase in NA levels. This effect could be due to the similarity of the chemical structure of HEPB to that of NA. The observed effects on brain NA concentrations suggest that HEPB acts on NA receptors or transporters and that these actions could involve other catecholamines. The proposed mechanism of action of HEPB is consistent with the data obtained from multiple experimental models that converge to demonstrate the antiepileptic role of endogenous NA (15). This effect mostly

a)

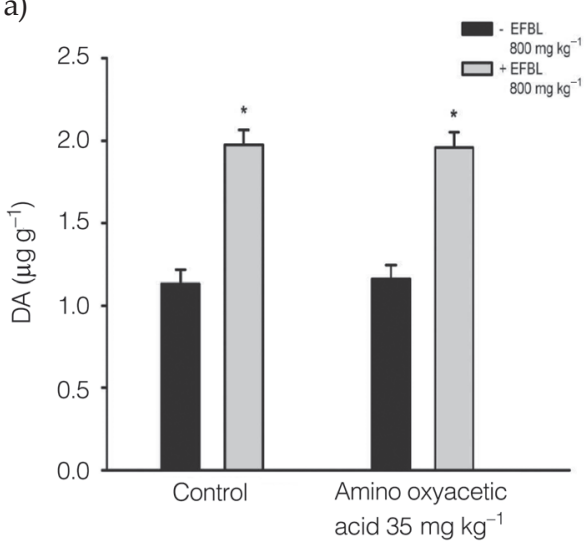

b)

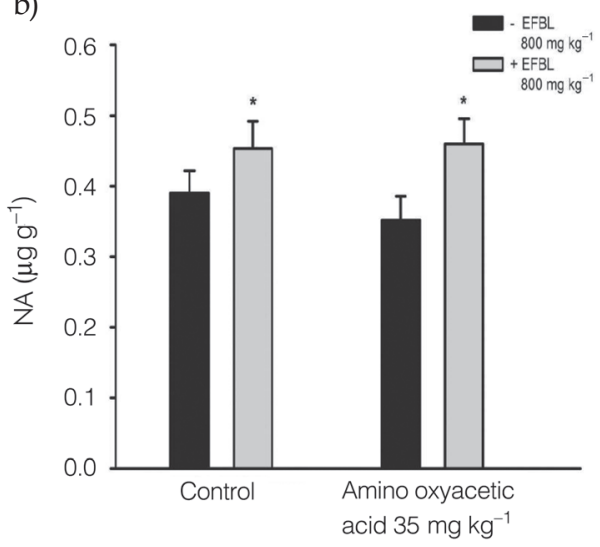

Fig. 5. Influence of amino-oxyacetic acid (AAOA) on the effect of $\gamma$-ethyl- $\gamma$-phenyl-butyrolactone (EFBL) on the brain levels of: a) dopamine (DA) and b) noradrenaline (NA). AAOA ( $\left.35 \mathrm{mg} \mathrm{kg}^{-1}\right)$ was administered to groups of five mice. One hour later, animals received a single administration of 800 $\mathrm{mg} \mathrm{kg}^{-1}\left(4.2 \mathrm{mmol} \mathrm{kg}^{-1}\right)$ of EFBL and were sacrificed 1 hour later (mean $\pm \mathrm{SEM}, n \geq 5$ ). Statistically significant difference $v$ s. control: ${ }^{*} p<0.05$. 
counteracts the development of an epileptic circuit rather than increasing the epileptic threshold.

In contrast to HEPB, which maintained increased levels of brain NA (Fig. 2b), EFBL did not cause significant modifications to brain NA, even several hours after being administered. Since the anticonvulsant doses of EFBL $\left(350 \mathrm{mg} \mathrm{kg}^{-1}, 2.1 \mathrm{mmol} \mathrm{kg}{ }^{-1}\right)$ did not modify NA levels significantly, it is believed that the anticonvulsant effect of EFBL is not related to its effects on NA levels. Ethyl and phenyl radicals on EFBL may cause a structural modification that could lead to a reduced interaction with NA metabolism. Considering the major role of DA in epileptogenesis, we propose that the anticonvulsant effect of EFBL is also mediated by DA. In addition to EFBL, other drugs that stimulate the dopaminergic system, such as apomorphine and amphetamines or even some antiparkinsonian drugs, exert anticonvulsant effects as well (13).

In 1996, a glutamate-DA interaction proposed by Starr attempted to explain the individual susceptibility to epilepsy in limbic areas (24). According to this hypothesis, in the epileptic brain there is increased tonic excitation of DA neurons by glutamate (Glu) due to the peroxisomal activity on the cortex. Thus, the phasic release of DA increases, leading to the downregulation of DA postsynaptic receptors and a decreased phasic response (25).

There are five main DA receptor subtypes, including D1-D5 isoforms (26). The results from a combination of studies performed in a wide variety of animal models have illustrated the opposing actions of D1-like and D2-like receptor signaling in epileptogenesis. Indeed, signaling from D1-like receptors is generally pro-epileptogenic, whereas D2-like receptor (D2R) signaling exerts an antiepileptogenic effect (25).

Among the experimental evidence that shows the anticonvulsant effect of D2R stimulation, perhaps the most important finding is the inhibitory effect on hippocampal excitability through activation of these receptors. Another important finding is the promotion of seizures observed in patients with no previous history of epilepsy via the use of antipsychotics that act as DA-ergic D2-like antagonists. In contrast, seizure inhibition has been observed when antiparkinsonian drugs, such as pergolide and bromocriptine, which both act by stimulating D2Rs, are administered (24).

According to the above findings, and considering that presynaptic receptors (autoreceptors) are mainly composed of the D2 subtype, a low dose of a D2R agonist would stimulate presynaptic autoreceptors, leading to a decreased release of DA while preventing the downregulation or desensitization of postsynaptic receptors (25). Because of the anticonvulsant effect of EFBL and its effects on brain DA levels, it is believed that the anticonvulsant actions of EFBL ultimately result in the activation of presynaptic D2 receptors.

This proposal is further supported by the influence of CPZ, whose most important mechanism of action is the blockade of DA presynaptic receptors. The results given in Fig. 3 show that EFBL is able to reverse the effects of $\mathrm{CPZ}$, reinforcing the idea that EFBL acts through the dopaminergic system and specifically on the DA presynaptic receptors, as does CPZ. Moreover, since D2 receptors are also present in the presynaptic perivascular endings that modulate NA release (27), the effects of EFBL on NA brain levels also point to the involvement of $\mathrm{D} 2$ receptors in the actions of EFBL.

Therapeutic use of inhibitors of MAO, a catecholamine-degrading enzyme, has increased over time due to their neuroprotective properties. PHEN is an irreversible, nonselective MAO inhibitor that has been used for many years as an antidepressant drug and 
is also effective in treating panic, social anxiety and post-traumatic stress disorders. In this study, EFBL potentiated the effects of PHEN on the brain levels of both DA and NA in an additive manner. These results indicate that the two drugs act synergistically on dopamine availability to increase D2 receptor activity.

In the case of NA, the catecholamine concentration after the administration of PHEN and EFBL was higher than expected based on the separate effects of each drug. One possible explanation is that EFBL may markedly increase NA concentration, but this excess is promptly removed by MAO. MAO inhibition thus exposes a contrasting increase. However, other possibilities, such as a dopaminergic action on NA synthesis or release, cannot be ruled out on the basis of the present data.

Although PHEN acts mostly as an MAO inhibitor, it has also been reported to inhibit GABA-transaminase, thus increasing brain GABA levels (28). Based on these data and our assumption regarding the mechanism of action of EFBL, the possibility thus persists that the effects of PHEN are influenced by changes in GABA-ergic activity. To explore this possibility, the effect of a classic T-GABA inhibitor, AAOA, was also investigated. As shown in Fig. 5, AAOA did not alter DA or NA brain levels, nor did it affect the actions of EFBL on these catecholamines. From this, we conclude that the activity of T-GABA and the changes in GABA-ergic activity do not play major roles in the effects of EFBL observed in this study.

$L$-Dopa has been useful as an adjunctive in the treatment of children with refractory absence seizures and has been suggested for ultrarefractory focal seizures in adults. Because of the described mechanism of action through activation of presynaptic D2 receptors, EFBL may represent a new therapeutic option for the control of convulsions in such difficult cases with no complementary drugs required. Besides its potential as an antiepileptic, EFBL may also represent a new treatment for Parkinson's disease, which would keep high brain DA levels for 24 hours, making it easier for the patient to adhere to the treatment, without the drawbacks of oral therapies.

\section{CONCLUSIONS}

Taken together, our results allow us to postulate that EFBL, which possesses anticonvulsant properties, acts on presynaptic dopaminergic receptors, thus increasing DA levels. These effects are maintained as long as 24 hours after administration, which could be a consequence of the presence of ethyl and phenyl radicals that retard its enzymatic degradation by lactonase. This prolonged effect on DA brain levels confers to EFBL not only anticonvulsant but also hypnotic properties. EFBL can thus be considered a potential alternative to a dopaminergic-stimulating drug, which could have therapeutic importance in the control of refractory seizures without complementary drugs and also for the treatment of reduced catecholaminergic activity such as that observed in Parkinson's disease, without the drawbacks of oral therapies.

Acknowledgements. - HEPB was synthesized in the Laboratory of Chemotherapy, Department of Biochemistry, National School of Biological Sciences of National Polytechnic Institute (Mexico), and kindly donated by Dr. Guillermo Carbajal-Sandoval.

This work was supported by the Section of Postgraduate Studies and Research, Academic Secretary of the National Polytechnic Institute, Mexico. 


\section{REFERENCES}

1. M. Dematteis, L. Pennel and M. Mallaret, Current knowledge on gamma-hydroxybutyric acid (GHB), gamma-butyrolactone (GBL) and 1,4-butanediol (1,4-BD), Rev. Prat. 62 (2012) 669-672.

2. F. Vega-Díaz and F. Vega-Rasgado, 4-Etil-4-fenil-butirolactona, nuevo anticonvulsionante, An. Esc. Nac. Cienc. Biol. Méx. 34 (1991) 23-35.

3. M. F. Vega-Díaz, L. A. Vega Rasgado and R. Yañez, La 4-etil-4-fenil-butirolactona, nuevo fármaco anticonvulsivo y sus relaciones con el metabolismo del GABA, Acta Med. XXX (1994) 9-18.

4. F. Vega-Díaz, S. García and F. Vega-Rasgado, Propiedades hipnóticas de la 4-etil-4-fenil-butirolactona, An. Esc. Nac. Cienc. Biol. Méx. 37 (1992) 155-170.

5. A. Schousboe, K. K. Madsen, M. L. Barker-Haliski and H. S. White, The GABA synapse as a target for antiepileptic drugs: a historical overview focused on GABA transporters, Neurochem. Res. 39 (2014) 1980-1987; DOI: 10.1007/s11064-014-1263-9.

6. A. Sarup, O. M. Larsson and A. Schousboe, GABA transporters and GABA-transaminase as drug targets, Curr. Drug Targets CNS Neurol. Disord. 2 (2003) 269-277; DOI: 10.2174/1568007033482788.

7. M. Avoli and M. de Curtis, GABAergic synchronization in the limbic system and its role in the generation of epileptiform activity, Prog. Neurobiol. 95 (2011) 104-132; DOI: 10.1016/j.pneurobio.2011.07.003.

8. V. Tancredi, G. G. Hwa, C. Zona, A. Brancati and M. Avoli, Low magnesium epileptogenesis in the rat hippocampal slice: electrophysiological and pharmacological features, Brain Res. 2 (1990) 280-290; DOI: 10.1016/0006-8993(90)90173-9.

9. M. Avoli, J. Louvel, I. Kurcewicz, R. Pumain and M. Barbarosie, Extracellular free potassium and calcium during synchronous activity induced by 4-aminopyridine in the juvenile rat hippocampus, J. Physiol. 493 (1996) 707-717; DOI: 10.1113/jphysiol.1996.sp021416.

10. M. E. Morris, G. V. Obrocea and M. Avoli, Extracellular $\mathrm{K}^{+}$accumulations and synchronous GABA-mediated potentials evoked by 4 -aminopyridine in the adult rat hippocampus, Exp. Brain Res. 109 (1996) 71-82; DOI: 10.1007/BF00228628.

11. Y. Ben-Ari, J. L. Gaiarsa, R. Tyzio and R. Khazipov, GABA: a pioneer transmitter that excites immature neurons and generates primitive oscillations, Physiol. Rev. 87 (2007) 1215-1284; DOI: 10.1152/physrev.00017.2006.

12. A. T. Gulledge and G. J. Stuart, Excitatory actions of GABA in the cortex, Neuron 37 (2003) 299-309; DOI: 10.1016/S0896-6273(02)01146-7.

13. Y. Bozzi, M. Dunleavy and D. C. Henshall, Cell signaling underlying epileptic behavior, Front. Behav. Neurosci. 5 (2011) Article 45 (11 pages); DOI: 10.3389/fnbeh.2011.00045.

14. M. A. Kurian, P. Gissen, M. Smith, S. Heales, Jr. and P. T. Clayton, The monoamine neurotransmitter disorders: an expanding range of neurological syndromes, Lancet Neurol. 10 (2011) 721-733; DOI: 10.1016/S1474-4422(11)70141-7.

15. F. S. Giorgi, C. Pizzanelli, F. Biagioni, L. Murri and F. Fornai, The role of norepinephrine in epilepsy: from the bench to the bedside, Neurosci. Biobehav. Rev. 28 (2004) 507-524; DOI: 10.1016/j. neubiorev.2004.06.008.

16. M. Pinon, I. S. Racotta, R. Ortiz-Butron and R. Racotta, Catecholamines in paraganglia associated with the hepatic branch of the vagus nerve: effects of 6-hydroxydopamine and reserpine, J. Auton. Nerv. Syst. 75 (1999) 131-135.

17. S. Qazi, M. Caberlin and N. Nigam, Mechanism of psychoactive drug action in the brain: simulation modeling of GABAA receptor interactions at non-equilibrium conditions, Curr. Pharm. Des. 13 (2007) 1437-1455; DOI: 10.2174/138161207780765972.

18. S. M. Simpson, A. J. Hickey, G. B. Baker, J. N. Reynolds and R. J. Beninger, The antidepressant phenelzine enhances memory in the double Y-maze and increases GABA levels in the hippocam- 
pus and frontal cortex of rats, Pharmacol. Biochem. Behav. 102 (2012) 109-117; DOI: 10.1016/j. pbb.2012.03.027.

19. M. P. Galloway, M. E. Wolf and R. H. Roth, Regulation of dopamine synthesis in the medial prefrontal cortex is mediated by release modulating autoreceptors: studies in vivo, J. Pharmacol. Exp. Ther. 236 (1986) 689-698.

20. R. L. Macdonald, M. J. McLean and J. H. Skerritt, Anticonvulsant drug mechanisms of action, Fed. Proc. 44 (1985) 2634-2639; DOI: 10.1016/0013-4694(85)90099-9.

21. J. O. McNamara, D. W. Bonhaus, B. J. Crain, R. L. Geliman and D. Shin, Biochemical and Pharmacologic Studies of Neurotransmitters in the Kindling Model, in Neurotransmitters and Epilepsy (Eds. P. C. Jobe and H. E. Laird II), Humana Press, Clifton (NJ) 1986, pp. 115-148.

22. C. Beas Zárate, J. Arauz-Contreras, A. Velazquez and A. Fería-Velasco, Monosodium L-glutamateinduced convulsions - II. Changes in catecholamine concentrations in various brain areas of adult rats, Gen. Pharmacol. 16 (1985) 489-493; DOI: 10.1016/0306-3623(85)90009-6.

23. C. Beas Zárate, R. Schliebs, A. Morales-Villagrán and A. Fería-Velasco, Monosodium L-glutamateinduced convulsions: changes in uptake and release of catecholamines in cerebral cortex and caudate nucleus of adult rats, Epilepsy Res. 4 (1989) 20-27; DOI: 10.1016/0920-1211(89)90054-5.

24. M. S. Starr, The role of dopamine in epilepsy, Synapse 22 (1996) 159-194; DOI: 10.1002/(SICI)10982396(199602)22:2<159::AID-SYN8>3.0.CO;2-C.

25. S. C. Chen, Epilepsy and migraine: The dopamine hypotheses, Med. Hypotheses 66 (2006) 466-472; DOI: 10.1016/j.mehy.2005.09.045.

26. M. P. DeNinno, R. Schoenleber, R. J. Perner, L. Lijewski, K. E. Asin, D. R. Britton, R. MacKenzie and J. W. Kebabian, Synthesis and dopaminergic activity of 3-substituted 1-(aminomethyl)-3,4dihydro-5,6-dihydroxy-1H-2-benzopyrans: characterization of an auxiliary binding region in the D1 receptor, J. Med. Chem. 34 (1991) 2561-2569; DOI: 10.1021/jm00112a034.

27. M.-Y. Arsenault, A. Parent, P. Séguéla and L. Descarries, Distribution and morphological characteristics of dopamine-immunoreactive neurons in the midbrain of the squirrel monkey (Saimiri sciureus), J. Comp. Neurol. 267 (1988) 489-506; DOI: 10.1002/cne.902670404.

28. G. B. Baker, J. T. Wong, J. M. Yeung and R. T. Coutts, Effects of the antidepressant phenelzine on brain levels of gamma-aminobutyric acid (GABA), J. Affect. Disord. 21 (1991) 207-211; DOI: 10.1016/0165-0327(91)90041-P. 